\title{
Influence of Groundwater Table Fluctuation on Performance of Bases and Subgrades
}

\author{
Sabry A. Shihata, Zaki A. Baghdadi And Ahmed M. Khan \\ Department of Civil Engineering, \\ King Abdulaziz University, Jeddah, Saudi Arabia.
}

\begin{abstract}
Water table levels fluctuate in areas where no storm and/or sewage systems exist causing significant variations in the moisture contents of the base and subgrade materials that lead to a major deterioration in the performance of pavements. In this paper, strength characteristics and basic properties of the soil are examined. The effect of the degree of saturation in the range of 50 to $100 \%$, on the resilient modulus of the soil, and the pavement deflection are studied utilizing the results of cyclic undrained triaxial tests with lateral pressures in the range $100-140 \mathrm{kN} / \mathrm{m}^{2}$.
\end{abstract}

\section{Introduction}

In developing areas without sufficient storm and/or sewage systems, waste water is disposed of locally and the storm water is left to percolate through the ground. This recharge raises the existing water table near or up to the ground surface if there is a shallow impermeable layer or if the groundwater table is already high. The problem also exists when the rate of discharge of the waste water is greater than the soil can dissipate. This causes significant variations in the moisture content of the soil which is used as a subgrade for the pavement of the street network and also on the base coarse as well, depending on the material used.

Rise of the water table affects adversely the performance of street pavements. If not taken into consideration, it causes premature failure of the pavement surface manifested as extensive alligator cracking and rutting. These types of distress are typical of the affected areas. Increasing moisture content in the soil reduces its resilient modulus and increases permanent strains. 
The effect of degree of saturation and compaction on the elastic modulus and permanent strain of the predominant soil in a badly affected area, by the rise of groundwater table, was studied using strain controlled cyclic undrained triaxial tests. The undrained tests were performed because of the dynamic nature of loading in the field and the low permeability of the soil. This is the first stage of a more comprehensive program which is going on to study the problem thoroughly.

Utilization of static triaxial testing for the determination of the resilient modulus and permanent deformation under repeated loading was done earlier by other investigators and many cases are cited in the literature.

It was possible, using the elastic properties as determined in this study, to assess the influence of the rise of water table on the deflection of the pavement surface and the vertical strain over the depth from which permanent strain and rutting potential may be evaluated.

\section{Review of Literature}

In this review of literature, two parameters, which are used extensively to assess the performance of bases, subbases and subgrades, are discussed; resilient modulus, $M_{r}$ and permanent strain, $\varepsilon_{p}$. The resilient modulus has been used for evaluating the dynamic response of materials in the laboratory. It is defined as the ratio of the repeated axial deviatoric stress, $\sigma_{d}$, to the recoverable or resilient axial strain $\varepsilon_{\mathrm{r}}$

or

$$
M_{r}=\sigma_{d} / \varepsilon_{r}
$$

Studies have indicated that resilient deformation generally stabilises after 200 load repititions and hence the $M_{r}$ value is usually computed at this repetition level.

Thomson and Robnett ${ }^{[1]}$ conducted an intensive study on the resilient properties of fine-grained soils ( $\mathrm{A}$ and $\mathrm{BC}$ horizons). They found that plots of $M_{r}-\sigma_{d}$ relations typically displayed a "breaking point" deviator stress where there was a substantial change in slope. The resilient moduli at the breaking point $M_{r}$, for all soils tested were found to occur at a stress level around $41 \mathrm{kN} / \mathrm{m}^{2}(6 \mathrm{psi})$. Several factors were found to affect the resilient properties of the soil studied. Some of these factors are: soil properties, shear strength, degree of saturation and compaction.

Degree of saturation has strong correlation with $M_{r}$, where for soils substantially wet of optimum, high degrees of saturation and low $M_{r}$ are characteristic regardless of level of compaction. Compaction level was not significant for $A$ horizon soils but was significant at all stress levels for the $B C$ horizon soils.

Haynes and Yoder ${ }^{[2]}$ found that bank-run gravel exhibits high moisture sensitivity, especially near the critical $80-85$ percent degree of saturation level, where the rate of decrease in the resilient modulus increases as the degree of saturation increases beyond the critical level.

Rada and Witczak ${ }^{|3|}$ conducted a comprehensive study on the results of 271 tests on different types of granular materials under different levels of compactions and degrees of saturation. Their analysis indicated an inverse correlation between $k_{1}$ and $k_{2}$ 
(constants in $M_{r}=k_{1} \theta \vee k_{2}$ ) exists for the global class of all granular materials, where $\theta$ is the bulk stress, and $k_{1}$ and $k_{2}$ are regression constants.

Also, they found that a relation exists between $\log k_{1}$ and both the degree of saturation $S_{r}$ and the logarithm of the unit volumetric compaction energy. Out of the tests results, the following regression model was developed:

$$
\log M_{r}=C_{0}+C_{1} S_{r}+C_{2} P C+C_{3} \log \theta
$$

Where $C_{0}, C_{1}, C_{2}, C_{3}$ are coefficients of regression depending on the type of soil tested.

$$
\begin{aligned}
& S_{r}=\text { degree of saturation (\%) } \\
& P C=\text { percentage compaction relative to modified density (\%) } \\
& \theta \quad=\text { bulk stress, or first stress invariant. } \\
& R^{2}=0.59 \text { to } 0.84 \text { for the different types of soils. }
\end{aligned}
$$

Permanent strain and hence the rut depth in granular layers are interdependent and should be controlled because of their significant influence on the safety and performance of the supporting system. As reported in the literature, some of the important factors that affect the magnitude of permanent strain in granular materials subjected to repeated loading may be summarized as follows:

\section{- Number of Loading Cycles}

A considerable amount of the total permanent strain takes place after the first few cycles and it increases with increasing magnitude of deviator stress ${ }^{[4,5]}$. A linear relationship has also been shown between permanent strain and the logarithm of the number of cycles up to 10000 cycles, by Lentz and Baladi ${ }^{[6]}$.

\section{- State of Stress}

Deviator stress and confining stresses are significant in determining the amount of permanent strains. They should be considered simultaneously in the analysis ${ }^{[7.8]}$.

\section{- Density}

Increasing density leads to decrease in permanent strain, Kalcheff ${ }^{|9|}$.

\section{- Amount of Fines passing \# 200}

Barksdale has found that the relation between plastic strain and amount of fines is stress dependent ${ }^{[8]}$. At low stress levels, the amount of fines had no effect, while at higher stress levels the rate of increase in plastic strain decreased as the amount of fines is more than $10 \%$.

\section{- Degree of Saturation}

Haynes and Yoder have shown that increasing the degree of saturation from about $70 \%$ to $95 \%$ resulted in large plastic strain increments ${ }^{[2]}$.

Hyperbolic functions and constitutive equations with parameters obtained from static triaxial tests have been used to predict permanent strains, e.g., Lentz and Baladi ${ }^{[6,10]}$. 


\section{Experimental Program}

The experimental program was carried out on a silty sand collected from Jeddah area as recent soils surveys carried out in Jeddah city revealed that at shallow depths $(0-4 m)$, silty sands are the predominantly occurring soils ${ }^{[11]}$. These soils have low permeability and do not permit free draining of groundwater which unfavourably produces rise of water table upon recharge. Therefore, silty sand was selected in this investigation. The identification and classification properties of this soil are summarized in Table 1. Figure 1 shows its grain size distribution and Fig. 2 shows compaction characteristics as obtained from modified AASHTO test specifications.

Table 1. Properties of the soil tested.

\begin{tabular}{lll}
\hline Location: Prince Sultan Street, Jeddah, Saudi Arabia \\
Color : light brown & \\
Liquid Limit & $=28 \%$ \\
Plastic Limit & $=21 \%$ \\
Plasticity Index & $=7$ \\
Shrinkage Limit & $=18 \%$ \\
Specific Gravity & $=2.64$ \\
Classification Groups : AASHTO & $=\mathrm{A}-2-4(0)$ \\
Max. Grain Size : Unified & $=\mathrm{SM}$ \\
$D_{10}$ & $=1 / 2^{\prime \prime}(14 \mathrm{~mm})$ \\
$C_{u}$ & $=0.02 \mathrm{~mm}$ \\
$C_{z}$ & $=70$ \\
$\%$ Clay & $=1.43$ \\
$\%-\# 200$ & $=5$ \\
& $=18$ \\
\hline
\end{tabular}

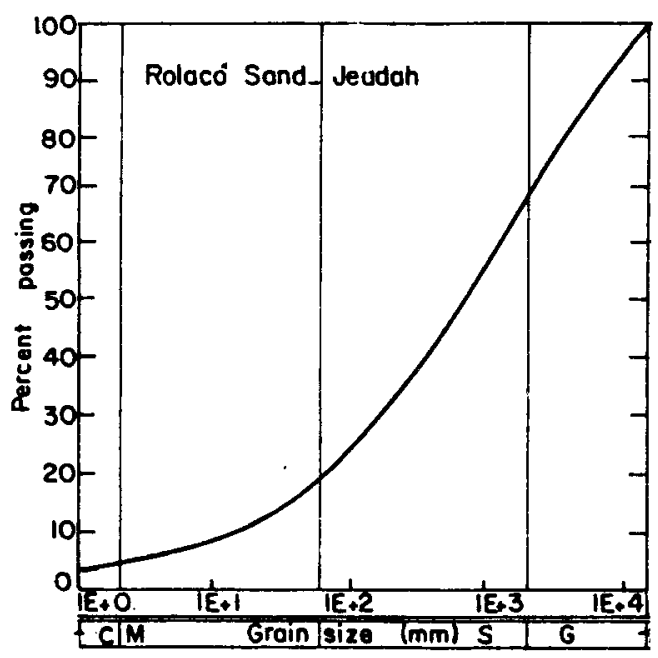

FIg. 1. Particle size distribution of test sand. 


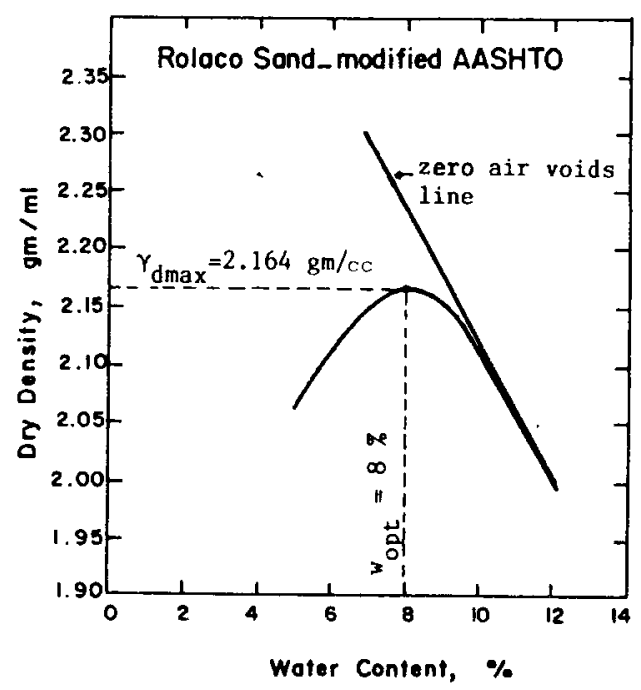

FIG. 2. Dry density-water content relationships.

The experimental part of the study included determination of the grain size distribution (sieve analysis and hydrometer), (Fig. 1), compaction (Fig. 2), and unconsolidated undrained triaxial test applying cyclic loads.

In order to explore the material characteristics over a range of degrees of compaction and saturation, it was planned to test at relative compactions of $90 \%, 95 \%$ and $100 \%$. The degrees of saturation were selected to be $50 \%, 75 \%$ and $100 \%$. For each degree of saturation and relative compaction, the amount of water and solids were worked out for preparation of triaxial test specimens. The various moisture contents for different degrees of saturation and compaction are listed in Table 2.

TABLE 2. Moisture contents for various degrees of saturation and relative compaction.

\begin{tabular}{|c|c|c|c|c|c|}
\hline $\begin{array}{c}\text { Dry } \\
\text { Density } \\
\text { gm/cc }\end{array}$ & $\begin{array}{c}\text { Relative } \\
\text { Compaction } \\
\%\end{array}$ & $\mathrm{~S}=50 \%$ & $\mathrm{~S}=75 \%$ & $\mathrm{~S}=90 \%$ & $\mathrm{~S}=100 \%$ \\
\hline 1.948 & 90 & 6.7 & 10.0 & 12.0 & 13.5 \\
\hline 2.024 & 95 & 5.7 & 8.6 & 10.3 & 11.5 \\
\hline 2.164 & 100 & 4.0 & 6.2 & 7.4 & 8.3 \\
\hline
\end{tabular}

The triaxial specimens were $50 \mathrm{~mm}$ diameter and $100 \mathrm{~mm}$ high; the diameter of the specimens was selected keeping in view the maximum aggregate size. The dry material was accurately weighed, to which pre-determined amounts of distilled water were added, before thorough mixing. The specimens were statically compacted. 
Strain controlled triaxial tests were carried out on the specimens using a rate of loading and unloading of $1.25 \mathrm{~mm} / \mathrm{min}$; the rate which is usually recommended for UU loading tests.

As the tests were of the controlled strain type, trial tests on similar specimens were first carried out to determine the magnitudes of peak deviator stresses and ultimate axial strains. It was observed that the specimens showed plastic bulging and shear failure. It was, therefore, decided to load specimens up to $15 \%$ axial strain as recommended in literature for the determination of peak deviator stress. Five cycles of loading were applied to each specimen. The procedure of loading and reloading consisted of first loading the specimen to about $1 \%$ axial strain and then unloading it to zero load, thus the value of permanent deformation would be available for each cycle. For the next cycle, the axial strain levels were increased to $2 \%, 3 \%, 4 \%$, and $5 \%$ and each time, the specimens were unloaded to zero deviator stress. After having completed the 5 cycles, static loading was applied until the axial strain was $15 \%$ and the test was then discontinued. A typical stress-strain curve is shown in Fig. 3. The tests were carried out on identical specimens with confining pressures of $100 \mathrm{kN} / \mathrm{m}^{2}$ and $140 \mathrm{kN} / \mathrm{m}^{2}$.

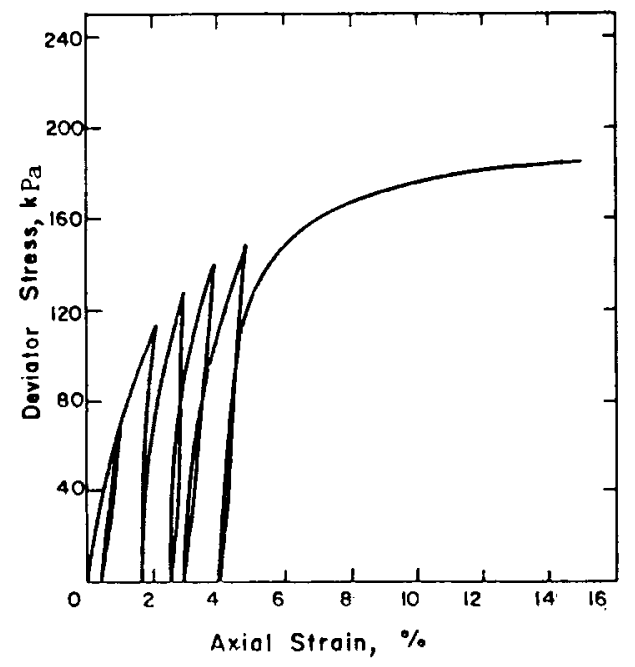

FIG. 3. Typical deviator stress-strain relationship from triaxial test.

\section{Results}

The elastic modulus, deviator stress and permanent strain at each strain level were determined. Corresponding values at a strain level of $9.8 \times 10^{-3}$ are given in Tables 3 , 4 and 5. Effect of the degree of saturation on the elastic modulus is shown in Fig. 4 using a confining pressure of $100 \mathrm{kPa}$. It is noticed that the slope of the three curves changes abruptly at a degree of saturation around $75 \%$. This is lower than the $80-$ 
$85 \%$ value cited in the literature ${ }^{[2]}$. Figure 5 shows the effect of the deviator stress and degree of saturation on the permanent strain. Figure 5 also shows that for each degree of saturation there exists a deviator stress at which the rate of increase in the permanent strain becomes infinite. This deviator stress may be called the critical stress. Effect of the degree of saturation and compaction on this critical stress is shown in Table 6 for a confining pressure of $100 \mathrm{kPa}$.

TABLE 3. Elastic modulus in MPa at $\varepsilon_{T}=9.8 \times 10^{-3}(1 \mathrm{MPa}=145 \mathrm{psi})$.

\begin{tabular}{|c|c|c|c|c|c|}
\hline $\begin{array}{c}\sigma_{3} \\
\mathrm{KPa}\end{array}$ & \multicolumn{1}{c|}{$S$} & $50 \%$ & $75 \%$ & $90 \%$ & $100 \%$ \\
\hline \multirow{3}{*}{100} & 2.164 & 181 & 147 & 71 & 16 \\
& 2.024 & 154 & 107 & 45 & 12 \\
& 1.948 & 74 & 53 & 43 & 8.7 \\
\hline \multirow{3}{*}{140} & 2.164 & 211 & 157 & 109 & 64 \\
& 2.024 & 153 & 74 & 55 & 38 \\
& 1.948 & 144 & 63 & 24 & 15 \\
\hline
\end{tabular}

TABLE 4. Deviator stress at KPa at $\varepsilon_{T}=9.8 \times 10^{-3}$.

\begin{tabular}{|c|c|c|c|c|c|}
\hline $\begin{array}{c}\sigma_{3} \\
\mathrm{KPa}\end{array}$ & \multicolumn{1}{c|}{$\gamma_{d}$} & $50 \%$ & $75 \%$ & $90 \%$ & $100 \%$ \\
\hline \multirow{3}{*}{100} & 2.164 & 596 & 383 & 200 & 96 \\
& 2.024 & 370 & 213 & 104 & 68 \\
& 1.948 & 222 & 148 & 65 & 8.7 \\
\hline \multirow{3}{*}{140} & 2.164 & 740 & 501 & 305 & 194 \\
& 2.024 & 414 & 185 & 109 & 98 \\
& 1.948 & 287 & 126 & 24 & 30 \\
\hline
\end{tabular}

TABLe 5. Permanent strain at $\varepsilon_{T}=9.8 \times 10^{-3}$.

\begin{tabular}{|c|c|c|c|c|c|}
\hline $\begin{array}{c}\sigma_{3} \\
\mathrm{KPa}\end{array}$ & $\gamma_{d}$ & $50 \%$ & $75 \%$ & $90 \%$ & $100 \%$ \\
\hline \multirow{3}{*}{100} & 2.164 & 6.5 & 7.2 & 7.0 & 3.9 \\
& 2.024 & 7.4 & 7.8 & 7.5 & 3.9 \\
& 1.948 & 6.8 & 7.0 & 8.3 & 8.8 \\
\hline \multirow{3}{*}{140} & 2.164 & 6.3 & 6.6 & 7.0 & 6.8 \\
& 2.024 & 7.1 & 7.3 & 7.8 & 7.2 \\
& 1.948 & 7.8 & 7.8 & 9.1 & 7.8 \\
\hline
\end{tabular}




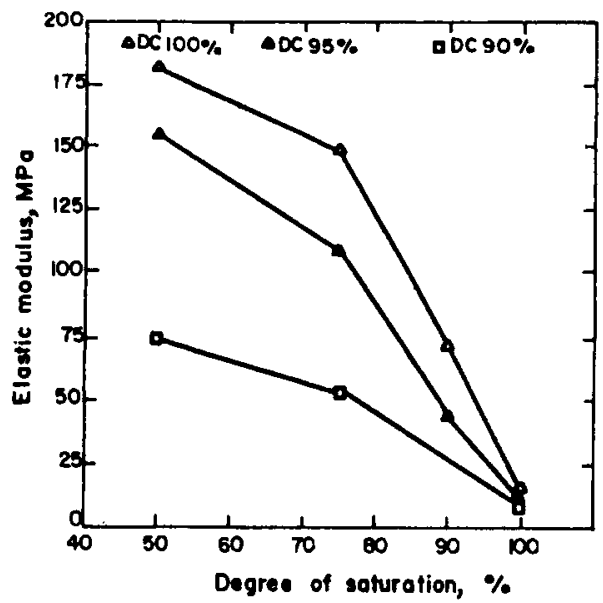

FIG 4. Effect of degree of saturation on elastic modulus.

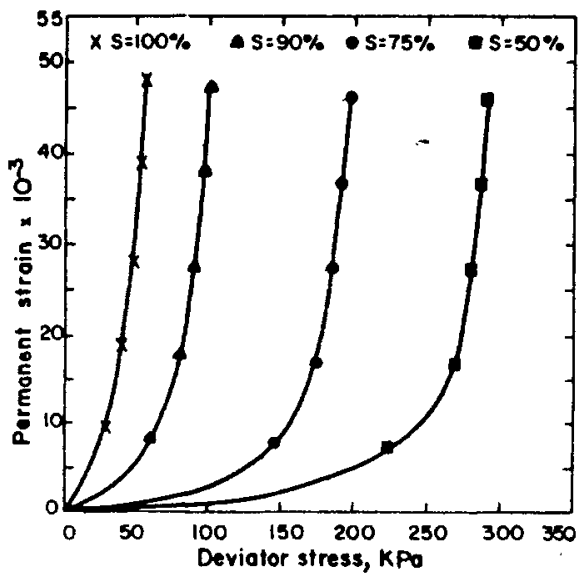

FIG. 5. Effect of deviator stress and degree of saturation on permanent strain.

TABLE 6. Effect of degree of saturation and dry unit weight on the critical deviator stress $\left(\sigma_{3}=100 \mathrm{KPa}\right)$.

\begin{tabular}{|r|r|r|r|r|}
\hline$\gamma_{d} S_{r}$ & $50 \%$ & $75 \%$ & $90 \%$ & $100 \%$ \\
\hline 2.164 & 845 & 638 & 441 & 246 \\
2.024 & 370 & 213 & 104 & 68 \\
1.948 & 222 & 148 & 65 & 26 \\
\hline
\end{tabular}


Regression analysis was performed on the test results to determine the relation between the resilient modulus, first stress invariant, degree of compaction, and degree of saturation for silty sand. The best model obtained was of the form:

$$
M_{r}=0.9642 D C+0.1413 \theta-0.9798 S_{r}
$$

where

$$
\begin{aligned}
M_{r} & =\text { resilient modulus in } \mathrm{MPa} \\
D C & =\text { degree of compaction (modified AASHTO (\%)) } \\
\theta & =\text { first stress invariant in } \mathrm{kPa} \\
S_{r} & =\text { degree of saturation }(\%) \\
R^{2} & =0.962
\end{aligned}
$$

To study the effect of water table on the performance of street pavements, the actual distribution of the degree of saturation with depth was determined at a location in Bani Malik street, Jeddah. The water table was 2.7 meters below the ground surface. The actual distribution is shown in Fig. 6, the shaded area indicates the extent of evaporation. Using this distribution, hypothetical profiles of the distribution of degree of saturation with depth assuming different levels of water table are also given in Fig. 6.

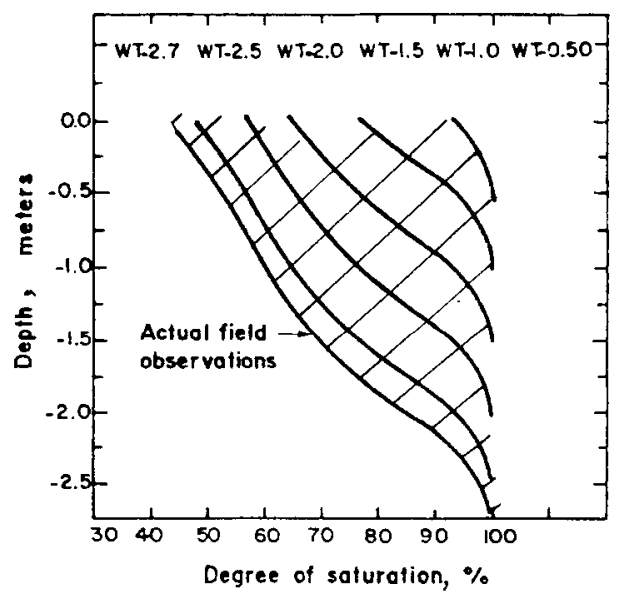

FIG 6. Variation of the degree of saturation with depth.

To illustrate the utilization of the results of this research in predicting the influence of the variations in the groundwater table on the performance of pavements, a pavement section at the location, where the water table was determined, was analysed theoretically using elastic layered program (ELSYM 5). Cross section of the pavement is shown in Fig. 7. The analysis was done for standard axle load of $81.7 \mathrm{kN}$ applied through dual wheels with tyre pressure of $0.57 \mathrm{MPa}$. Properties of surface layer and the aggregate base were kept constant. The depth of the subgrade was 
taken as $2500 \mathrm{~mm}$. The subgrade was divided into five layers of equal thickness. Resilient modulus for each layer was determined utilizing Fig. 6 and Fig. 4 depending on the depth of the water table.

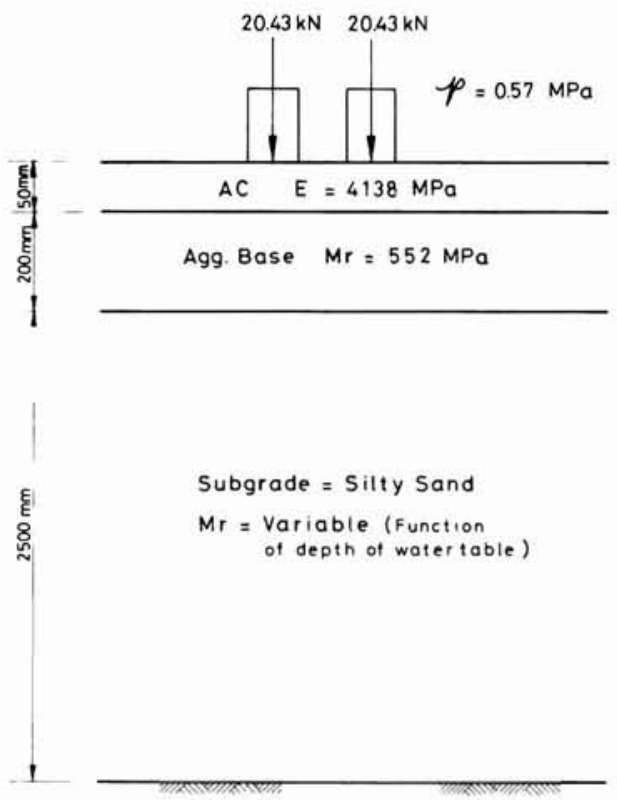

FIG. 7. Details of the X-section of the analysed pavement.

The effect of the level of water table on surface deflection is shown in Fig. 8. The figure shows that the rise of the water table causes larger deflections of the pavement surface and that there is a critical depth of the water table above which the rate of increase in surface deflection becomes excessive.

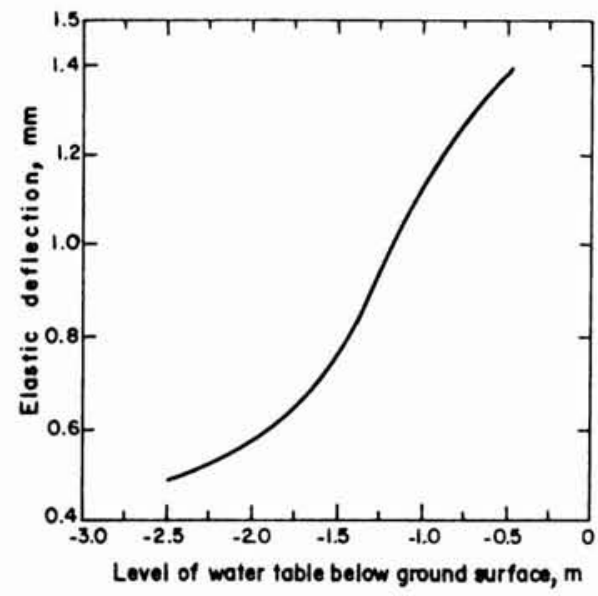

FIG. 8. Effect of the level of water table on the deflection of the pavement surface. 
Effect of the rise of water table on vertical strains, from which rutting potential of the pavement surface is éstimated is illustrated in Fig. 9. The figure shows that the rise of the water table causes higher strains over greater depths which, in turn, means higher potential for rutting.

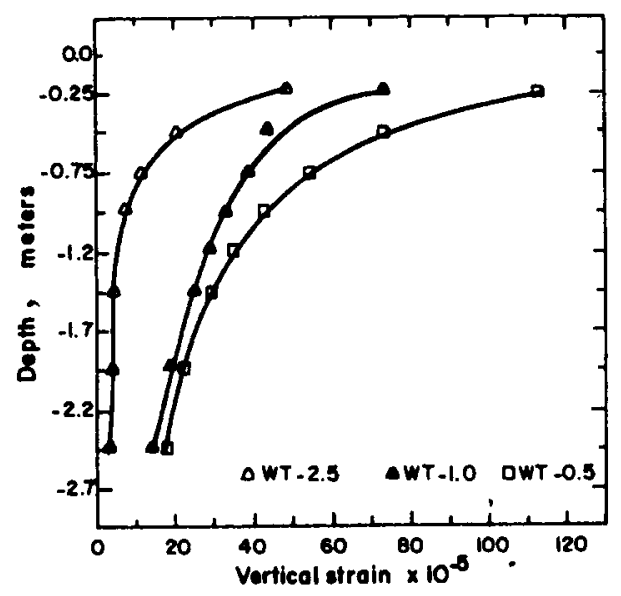

FIG. 9. Effect of the level of water table on the variation of vertical strain with depth.

\section{Conclusion}

In the light of this study, the following conclusion may be drawn:

1. Strain controlled repetitive undrained triaxial tests may be used to evaluate the resilient modulus of the type of soil tested and it is in general agreement with the literature.

2. The critical degree of saturation for the soil tested was $75 \%$ which is lower than the $80-85 \%$ cited in the literature.

3. There exists a critical depth of the water'table, based on surface deflection below which the pavement will deteriorate at an excessive rate.

\section{References}

[1] Thompson, M.R. and Robnett, Q.L., Resilient Properties of Subgrade Soils, Final Report, University of Illinois at Urbana-Champaign, June (1976).

[2] Haynes, J.H. and Yoder, E.J., Effects of Repeated Loading on Gravel and Crushed Stone Base Course Materials Used in the AASHTO Road Test, Highway Research Record 39: 82-96 (1963).

[3] Rada, G. and Witczack, M.W., Comprehensive Evaluation of Laboratory Resilient Moduli Results for Granular Materials, TRB Transportation Research Report 810: 23-32 (1981).

[4] Olowekerc, D.O., Strength and Deformation of Railway Ballast Subjected to Triaxial Loading, M.S. Thesis, Queen's University, Kingston, Ontario (1975).

[5] Brown, S.F., Repeated Load Testing of a Granular Material, Journal of the Geotechnical Engineering Div., ASCE (GT7): 825-841 (1974).

[6] Lentz, R.W. and Baladi, G.Y., Prediction of Permanent Strain of Sand Subjected to Cyclic Loading, TRB Transportation Research Report 749: 54-58 (1980).

[7] Thompson, M.R., Repeated Triaxial Testing Program Traprock Ballast Gradation Effects Study, University of Illinois at Urbana-Champaign, May 17 p. (1979). 
[8] Barksdale, R.D., Repeated Load Test Evaluation of Base Course Materials, Final Report, GIT, May (1972).

[9] Kalcheff, I.V., Characteristics of Graded Aggregates as Related to Their Behaviour Under Varying Loads and Environments, Presented at Conference on Utilization of Graded Aggregate Base Materials in Flexible Pavements, Oak Brook, Illinois, March 25-26 (1974).

[10] Lentz, R.W. and Baladi, G.Y., Constitutive Equation for Permanent Strain of Sand Subjected to Cyclic Loading, TRB Transportation Research Report 810: 50-54 (1981).

[11] Abu Rizaiza, O., et al., Study of Groundwater in Jeddah, Final Report, Submitted to the Directorate of Water and Sewage, Jeddah (1986) unpublished. 


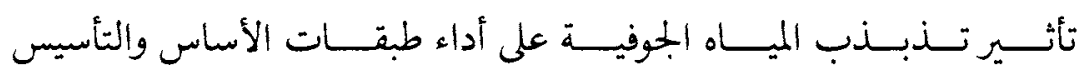

صبري أحمد شحاتة ، زكي عبد الله بغدادي و أحمد نحتار خحان

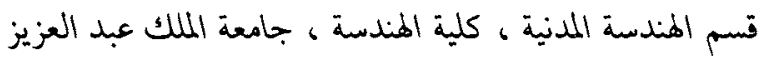

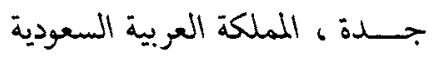

يتذبذب منسوب المياه الجوفية في المناطق التي لا تتوافر فيها أنظمة صرف مياه الأمطار مؤدياً

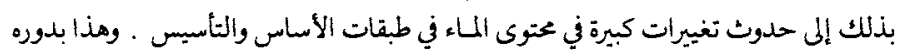

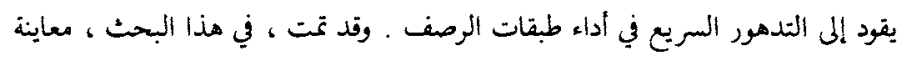

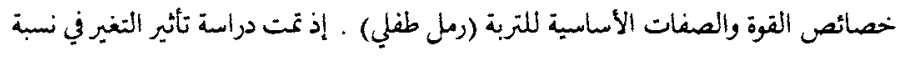

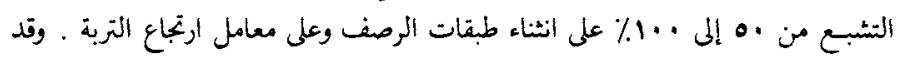

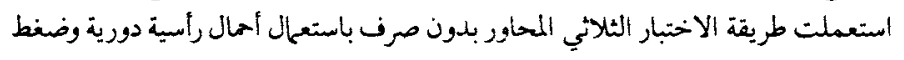

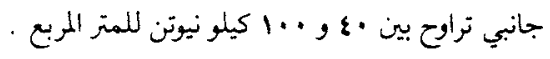

